Rodolfo Andrade de Gouveia Vilela ${ }^{1}$ Reginalice Cera da Silva ${ }^{2}$ José Marçal Jackson Filho ${ }^{3}$

\section{Poder de agir e sofrimento: estudo de caso sobre Agentes Comunitários de Saúde}

\author{
"Pouvoir d'agir" and suffering: study case on Community \\ Health Agents
}

${ }^{1}$ Doutor em Saúde Coletiva. Ergonomista. Professor do Departamento de Saúde Ambiental da Faculdade de Saúde Pública da Universidade de São Paulo (USP), São Paulo, SP.

${ }^{2}$ Mestre em Saúde Pública. Ergonomista. Centro de Referência em Saúde do Trabalhador (Cerest) de Piracicaba, Piracicaba, SP.

${ }^{3}$ Doutor em Ergonomia. Pesquisador da Fundacentro, Rio de Janeiro, RJ.

\section{Contato:}

Rodolfo Andrade de Gouveia Vilela

Rua Dr. Arnaldo, 715 - Pinheiros, São

Paulo, SP

CEP: 01246-904

E-mail:

ravilela@usp.br

\section{Resumo}

Os Agentes Comunitários de Saúde (ACS) possuem uma missão de grande importância na implementação da Estratégia de Saúde da Família: devem criar o vínculo entre a população e os serviços de atenção básica, combinando ações de promoção da saúde, assistência básica e prevenção. A equipe do Cerest de Piracicaba realizou, no período de 2004-2006, análise ergonômica do trabalho em uma unidade de saúde de família cujos objetivos foram compreender a relação entre queixas de sofrimento e as condições de trabalho das ACS e propor medidas para modificá-las. Os resultados da AET mostram que, a despeito do engajamento visando resolver os problemas de saúde das famílias, o limitado "poder de agir" das ACS, devido às limitações da unidade e da rede de serviços, expunham-nas a situações nas quais se encontravam incapazes de adotar ações efetivas e nas quais não podiam se prevenir do sofrimento.

Palavras-chave: saúde mental; Análise Ergonômica do Trabalho; saúde dos trabalhadores; saúde da família.

\begin{abstract}
Community Health Agents (CHA) play a very important role in implementing a Family Health Policy: they have to establish a link between users and primary care services, articulating health promotion, primary care, and preventive actions. From 2004 to 2006, a team from Cerest (Center of Reference in Workers' Health) in Piracicaba, São Paulo, carried out an Ergonomic Work Analysis (EWA) at a family health care center aiming not only at understanding the relationship between suffering complaints and CHA working conditions, but also at improving them. The results of EWA showed that despite being engaged in health promotion and in solving families' health problems, their 'pouvoir d'agir' was constrained, due to the limitations of the health care system that does not provide them with means to take effective action, causing suffering to the CHA.
\end{abstract}

Keywords: mental health; Ergonomic Work Analysis; occupational health; Family Health Program. 


\section{Introdução}

A Estratégia Saúde da Família (ESF) foi criada em 1994 como caminho para implementar os preceitos da Reforma Sanitária e contribuir para a viabilização do Sistema Único de Saúde (SUS) e superar a crise da saúde pública brasileira decorrente do modelo centrado no hospital e no trabalho do médico (VIANA; DAL POZ, 1998).

Em maio de 2008, após 14 anos da implantação da Saúde da Família, 28.100 equipes contando com 218.300 Agentes Comunitários da Saúde (ACS) atenderam mais de 90 milhões de pessoas no país (BRASIL, 2008). Sua missão é assegurar o acesso da população aos serviços de atenção básica, combinando ações de promoção da saúde, assistência básica e prevenção. Segundo o Ministério da Saúde, a ESF adequadamente estruturada tem condições de solucionar $85 \%$ dos casos de saúde da população atendida (BRASIL, 2001).

Embora indicadores de morbimortalidade mostrem que, demodogeral, aimplantação de Unidades deSaúde da Família (USF) tem contribuído para a melhoria das condições de saúde da população, estudos recentes sobre a ESF discutem diversos problemas de funcionamento e organização que colocam em risco não apenas sua eficiência (PEDROSA; TELES, 2001; RIBEIRO et al., 2004; SILVA; TRAD, 2005; TRAVERSO-YÉPEZ; BERNARDINO; GOMES, 2007; OLIVEIRA; ALBUQUERQUE, 2008), mas também a saúde dos seus trabalhadores (CAMELO; ANGERANI, 2004; SANTOS et al., 2007; TOMASI et al., 2008), em especial dos ACS (MARTINES; CHAVES, 2006; JARDIM; LANCMAN, 2009).

Nota-se, por meio destes estudos, que embora os ACS possuam missão de grande importância, não dispõem necessariamente dos meios para cumpri-la em sua integralidade. Parece existir relação entre seu "poder de agir" e seu adoecer, em especial de ordem mental (CLOT, 2008). Como consequência, a prevalência de agravos à saúde nesta comunidade profissional representa atualmente uma importante demanda para os serviços públicos de atenção à saúde do trabalhador.

Neste texto, são apresentados os resultados de estudo ergonômico realizado por um Centro de Referência em Saúde do Trabalhador (Cerest) cujo objetivo foi analisar o trabalho de profissionais de uma equipe de ACS de uma USF do município de Piracicaba para compreender a relação entre queixas de sofrimento e as condições de trabalho das ACS e propor medidas para modificá-las. Antes de apresentar e discutir esse caso, revisão sobre o papel dos ACS e referencial teórico sobre o trabalho e saúde serão feitos.

\section{Papel dos ACS, condições de trabalho e riscos à saúde}

A ESF configura-se como uma nova estratégia de implantação do SUS que procura a "mudança do objeto de atenção, forma de atuação e organização geral dos serviços, reorganizando a prática assistencial em novas bases e critérios" (BRASIL, 1997, p. 9). Nele, "a família passa a ser o objeto precípuo de atenção, entendida a partir do ambiente onde vive" (BRASIL, 1997, p. 9). Ações de assistência são combinadas a ações de prevenção e de promoção à saúde realizadas por equipe multiprofissional composta ao menos por um médico, um enfermeiro, um auxiliar de enfermagem e de 5 a 6 ACS.

Nessa nova perspectiva, o vínculo com a população e a criação de laços de compromisso e corresponsabilidade entre profissionais e a população são premissas fundamentais (NUNES et al., 2002; SILVA; DAMASO, 2002; CAMPOS, 1997; RIBEIRO; PIRES; BLANK, 2004; SCHIMITH; LIMA, 2004; VALENTIM; KRUEL 2007). O vínculo é visto como uma das formas de comprometimento dos trabalhadores com a missão e com os projetos institucionais (CAMPOS, 1997).

Segundo as diretrizes operacionais propostas pelo Ministério da Saúde (BRASIL, 1997), as equipes de saúde da família devem cadastrar a população adscrita a fim de identificar as características da população e de sua saúde e de estabelecer vínculo com ela. Esse processo é fundamental para o planejamento das ações a serem desenvolvidas. Do mesmo modo, novas atribuições devem ser desenvolvidas. Entre elas, a realização de visitas domiciliares e a participação em grupos comunitários.

Dentro desse programa, os ACS têm atribuições bastante específicas a fim de desenvolverem "suas atividades nos domicílios de sua área de responsabilidade, e junto à unidade para programação e supervisão de suas atividades" (BRASIL, 1997, p. 18). As visitas domiciliares ocupam espaço central no trabalho dos ACS, que devem: realizar mapeamento de sua área; cadastrar e atualizar as famílias; identificar indivíduos e famílias expostos a situações de risco; realizar acompanhamento mensal de todas as famílias sob sua responsabilidade; coletar dados para análise da situação das famílias acompanhadas; desenvolver ações básicas de saúde com ênfase na promoção da saúde e na prevenção das doenças; promover educação em saúde e mobilização comunitária; incentivar a participação e o fortalecimento dos conselhos de saúde; orientar as famílias para a utilização adequada dos serviços de saúde; participar da programação das ações de sua USF.

Uma vez que pertencem à comunidade onde trabalham - pré-requisito para sua contratação -, os ACS são considerados fundamentais para o sucesso desse novo modelo de atenção, pois têm como papel central a mediação entre comunidade e serviço de saúde (NUNES et al., 2002), em outras palavras, "são o elo" ou a "ponte" entre eles (SILVA; DAMASO, 2002). São protagonistas intrigantes "no que se refere à relação de trocas estabelecidas entre saberes populares de saúde e saberes médico-científico" (NUNES et al., 2002, p. 1640).

Suas atribuições possuem, assim, segundo Silva e Damaso (2002, p. 77), três dimensões: uma dimensão 
técnica, "relacionada ao atendimento aos indivíduos e famílias, à intervenção para prevenção de agravos ou para o monitoramento de grupos ou problemas mais específicos", fundamentada em conhecimentos técnico-científicos sobre a saúde; uma dimensão política associada não apenas à "inserção da saúde no contexto geral de vida, mas também, no sentido de organização da comunidade, de transformação dessas condições”. Outra dimensão - a de assistência social - também pode ser encontrada na prescrição da prática dos ACS com o objetivo de:

juntar as perspectivas de atenção primária e da saúde comunitária, buscando resolver questões, como o acesso aos serviços, no que lhe corresponde de racionalidade técnica, mas também integrando as dimensões de exclusão e cidadania. (SILVA; DAMASO, 2002, p. 77)

Para colocar em prática as exigências da ESF, os ACS têm como principal meio as "visitas domiciliares" para construir e manter as relações com usuários (indivíduos e famílias), passo fundamental para a construção e a manutenção do vínculo entre serviço e usuários. Na visita à casa das famílias, os ACS obtêm, de um lado, informações fundamentais para ações de prevenção, de assistência e, de outro, servem-se delas para orientar as famílias, ou seja, para promover ações educativas (AZEREDO et al., 2007). A eficiência da ação dos ACS depende da sua proximidade com as pessoas sob sua responsabilidade, depende da confiança neles depositada pelos usuários e suas famílias (NUNES et al., 2002).

Alguns estudos mostram que esse trabalho relacional aliado a outros determinantes de ordem técnica e organizacional podem estar associados ao adoecimento ou ao sofrimento dos ACS. Por um lado, não é possível definir os limites nas relações que se estabelecem entre ACS e usuários. "A entrada no mundo familiar traz inevitavelmente consigo a intimidade das pessoas, o seu mundo privado, e, com ele, novas construções relacionais permeadas de significados e sentimentos." (NUNES et al, 2002, p. 1644). A difícil "gestão das relações" explica os sentimentos de impotência, cansaço e tensões nas próprias vidas pessoais (MARTINES; CHAVES, 2006). Ou seja, segundo Silva e Damaso (2002, p. 81), "sua atuação implica envolvimento pessoal e desgaste emocional”.

Além disso, o envolvimento pode ser ininterrupto, pois os ACS moram no bairro onde atuam profissionalmente; seu mundo privado também é "invadido" pelas pessoas e seus problemas (JARDIM; LANCMAN, 2009). Encontram-se "literalmente" impossibilitados de "manter a distância” dos usuários.

O desgaste parece estar ainda associado à exposição dos ACS à precariedade das condições de vida, que determinam as condições de saúde e são reflexo das desigualdades sociais (TRAVERSO-YÉPEZ; BERNARDINO; GOMES, 2007). Como se encontram na interface entre o serviço de saúde e a população, os ACS estão, dessa forma, expostos à pressão dos usuários diante da precariedade do funcionamento do serviço, das demais instâncias do setor de saúde e de outros setores do Esta- do (RIBEIRO, 2004; TRAVERSO-YÉPEZ; BERNARDINO; GOMES, 2007; MARTINES; CHAVES, 2006; OLIVEIRA; ALBUQUERQUE, 2008), cuja capacidade de prestação de serviços é ultrapassada em alguns casos pela demanda da população (OLIVEIRA; ALBUQUERQUE, 2008).

Vivenciam impedimentos às suas ações devido à qualidade do espaço (TRAVERSO-YÉPEZ; BERNARDINO; GOMES, 2007) e à falta de meios (JACKSON; BARCELOS, 1999), além de estarem submetidos a imposições de metas que não são colocadas em discussão e refletem um modo de organização baseado na produtividade, na cobrança repetida, na racionalização extrema (SANTOS; SOARES; CAMPOS, 2007). Nessas condições, é quase que natural a existência de conflitos nas equipes cuja ori gem pode estar tanto na ausência de recursos para agir, como nas diferentes concepções que possuem sobre seu objeto de trabalho (SCHIMITH; LIMA, 2004), o que dificulta o desenvolvimento da dimensão coletiva do trabalho.

Os estudos citados mostram como as relações estabelecidas com usuários e familiares podem ser, de um lado, fonte de prazer e de sentido e, de outro, fonte de sofrimento e conflito para as agentes. Apontam, também, como causa para queixas e adoecimento das ACS, os diversos fatores que diminuem seu poder de agir (CLOT, 2008).

No entanto, a maior parte dos estudos apresentados baseia-se na percepção ou nos relatos dos agentes a respeito do seu trabalho e não na observação das interações realizadas junto aos usuários. Para melhor compreender os impasses que vivenciam na origem do adoecimento, torna-se fundamental compreender o que se passa nas suas situações reais de trabalho.

\section{Poder de agir e adoecimento no trabalho}

Alguns estudos recentes, fundados na análise do trabalho, têm mostrado a relação entre o poder de agir e suas limitações - os impedimentos no trabalho, a falta de meios e recursos para agir - e o adoecimento dos trabalhadores nos sistemas modernos de produção industrial e de serviços. Antes de apresentá-los e discuti-los, é fundamental precisar o conceito de atividade de trabalho.

\section{Atividade de trabalho: entre determinação social e margem de ação}

Para a Ergonomia da Atividade Profissional, todo trabalho contém certa determinação social, isto é, vários fatores que influenciam a realização das tarefas pelos trabalhadores são definidos exteriormente a eles.

Nas empresas e instituições, a tarefa dos trabalhadores, suas atribuições, resultam do trabalho de outros atores, sejam gestores, engenheiros, dentre outros profissionais. No entanto, para responder as finalidades da empresa ou instituição, enfrentando a grande variabilidade de situações, os trabalhadores, quando possível, redesenham os próprios objetivos da tarefa, desenvolvem estratégias ou formas de regulação, mobilizam-se individual ou coletivamente para agir. 
Daniellou (2005) define atividade de trabalho, conceito-chave em ergonomia, como a mobilização das capacidades físicas, cognitivas, emocionais e sociais de cada trabalhador para atender ao que lhe é solicitado pela empresa. Dessa forma, a atividade de trabalho realizada é necessariamente diferente do prescrito pelas instâncias de gestão.

Toda ação no trabalho tem "sentido", isto é, ela é sempre uma resposta a finalidades que podem envolver lógicas diversas (produção, qualidade, segurança, custo etc.), por vezes contraditórias entre si, determinadas por fatores externos (equipamentos, organização, ambiente), pelas exigências da hierarquia e pelos próprios trabalhadores (individual ou coletivamente) que condicionam sua atividade. Além disso, conforme Clot (2008):

a atividade é dirigida, simultaneamente para seu objeto e para as outras atividades portadas para este objeto, sejam de outra pessoa ou ainda outras atividades do sujeito. (p. 6)

Por isso, os trabalhadores procuram, quando possível, valer-se de estratégias que não são prescritas a fim de assegurar a qualidade de seu trabalho. Guedes, Lima e Assunção (2005) mostram a importância de estratégia desenvolvida pelo pessoal de enfermagem de um hospital privado, baseada na constituição de 'farmacinha' informal, diante da introdução de nova política de centralização de estoque de medicamentos. Como a obtenção dos medicamentos deveria obedecer a um fluxo burocrático e moroso, a existência de medicamentos disponíveis, mantidos informalmente, permitia que fossem ministrados mais rapidamente em situações de urgência, diminuindo o sofrimento dos pacientes.

Estratégias como a relatada mostram como os trabalhadores, quando possível, redefinem suas atividades para serem mais eficazes e asseguraram o espaço para a "lógica dos cuidados à saúde", mantendo-a em primeiro plano. Aliás, como veremos adiante, esta é característica fundamental nas situações de serviço de saúde.

Enfim, é importante também destacar a "função psicológica do trabalho", que ocupa papel central no desenvolvimento da capacidade de ação dos sujeitos e de sua personalidade. Atividade e subjetividade são inseparáveis (CLOT, 2006).

\section{Impedimentos e falta de meios: a diminuição do poder de agir e o adoecer}

Para Clot (2008), o que está em jogo atualmente é "o desenvolvimento do poder de agir dos sujeitos em situação" (p. 12), ou seja, a necessidade de assegurar aos trabalhadores a necessária margem de ação e os meios para agir nas situações de trabalho.

No entanto, o que se observa nas situações com alta prevalência de agravos é o oposto: a carência de meios e recursos e a utilização de modos de organização que produzem impedimentos para a ação e levam à diminuição da margem de ação dos trabalhadores.
Estudos sobre a ESF relatam a carência de recursos e meios, quase que como norma de funcionamento. Se, de um lado, a falta de 'medicamentos, material para curativo e teste do pezinho' aumentam a carga de trabalho, de outro, a dificuldade de conseguir consultas e cirurgias pode tornar sem sentido o trabalho dos ACS e da equipe de saúde da família (JACKSON; BARCELOS, 1999). Embora engajada na proteção da comunidade, a impossibilidade de assistir determinados pacientes leva a situações de perda de sentido - em dada situação, um ACS toma conhecimento do falecimento do paciente no momento em que comunica o agendamento da cirurgia que deveria salvar-lhe a vida. A frequência de tais situações pode explicar o absenteísmo e o sofrimento naquela unidade.

Em certos sistemas, os modos de gestão e de organização podem impedir as atividades de trabalho. Sznelwar, Abrahão e Mascia (2006) mostram que, no setor de teleatendimento, a limitação do tempo de atendimento, a prescrição extrema da interação por meio de scripts, dentre outros fatores, tornam-se impedimentos para o trabalhar, diminuindo a capacidade de resposta aos clientes e colocando os trabalhadores em dificuldade. A pouca efetividade desse modo de organização pode ser observada por meio do alto nível de retrabalho e do grande número de afastamentos de trabalhadores devido a problemas musculoesqueléticos e de saúde mental.

Ao refletir sobre intervenções ergonômicas em sistemas de produção industrial, visando a enfrentar a alta prevalência de problemas musculoesqueléticos, Daniellou (1999) propõe a ideia de "patologia organizacional”. Mostra que, nessas situações, é observada uma "síndrome geral de sensação de impotência", isto é, não sofrem apenas os trabalhadores, mas também a hierarquia intermediária e a própria direção da empresa.

Nessas situações críticas, nota-se um modo de funcionamento paradoxal, que se caracteriza por (DANIELLOU, 1999, p. 36):

1) Fonte de perda de produtividade não detectada pela empresa;

2) Tentativa de compensação por meio de pressão direta sobre os ritmos de trabalho ou sobre os efetivos;

3) Agravamento da perda de produtividade devido aos efeitos secundários dessa pressão.

Se trabalhar consiste, segundo Daniellou (1999), em uma dinâmica que envolve poder-pensar, poder-agir e poder-debater, nas situações por ele analisadas tal dinâmica está bloqueada. A despeito da falta de meios e de recursos para agir, a mensagem veiculada pela direção é "tendo ou não vassoura, varra de qualquer jeito".

No caso de serviços de cunho social, Clot (2006, p. 17) mostra a associação entre incidências psicopatológicas e a "amputação da atividade possível". Mostra, como Daniellou (1999), que o funcionamento organizacional está na origem dos problemas: 
os agentes a serviço do público não são tão somente "ultrapassados" por exigências exteriores. Eles não se acham apenas em dificuldades em termos de resposta. Eles esperam também que suas perguntas e sua contribuição sejam entendidas e reconhecidas. Não se deve afastar depressa demais a hipótese segundo a qual sua atividade se acha amputada por organizações "transbordadas" que não sabem mais responder nem às questões vindas do real, nem às exigências sociais do trabalho dos profissionais que elas empregam. (p. 17)

Situação similar vivem os trabalhadores da saúde, sobretudo pública, cujo estado de saúde é motivo de preocupação diante do aumento da prevalência de agravos à saúde, em especial das incidências psicopatológicas (ASSUNÇÃO; LIMA, 2010).

Nessas "situações de serviço", a dimensão cognitiva cede espaço para a dimensão subjetiva decorrente da natureza desta atividade de coprodução do serviço, que pode ser evidenciada pelo engajamento na relação, pela forma de condução das interações e pela expressão de aspectos emocionais em situação (CERF; FALZON, 2005).

Observa-se no trabalho de algumas categorias de saúde, como no caso do pessoal de enfermagem, a tensão entre "cuidar do outro" e "cuidar de si". O engajamento e a implicação pessoal observados nos cuidados se expressam na prioridade em assistir ao outro em detrimento do cuidado do próprio trabalhador (TEIGER; CLOUTIER; DAVI, 2005). Como mostra Molinier (2008), o cuidar é movido principalmente pela compaixão. Os impedimentos ao cuidar podem ter graves consequências para os trabalhadores.

Por isso, para Clot (2006, p. 17), é fundamental analisar não apenas a atividade realizada, mas também a que não se realiza, a "atividade contrariada". Sua compreensão pode explicar o sofrimento associando-o ao poder de agir dos trabalhadores.

"Quando as atividades estão impedidas, confinadas, encarceradas”, o sofrimento que delas decorre é uma forma de "amputação do poder de agir" do sujeito: "é por meio do inventário de numerosas situações deste tipo que se pode colocar o problema do sofrimento"... à maneira de P. Ricoeur, pode-se pensar que "o sofrimento não é unicamente definido pela dor física ou mental mas, pela diminuição, seja pela destruição da capacidade de agir, do poder-fazer, percebidos como agravo à integridade de si" (CLOT, 2008, p. 28).

\section{Metodologia}

A Análise Ergonômica do Trabalho - AET (GUÉRIN et al., 2001) da equipe de ACS de uma USF do município de Piracicaba foi realizada por dois técnicos do Centro de Referência em Saúde do Trabalhador (Cerest) de Piracicaba, atendendo à demanda de uma ACS participante da I Conferência de Saúde do Trabalhador e Saúde Ambiental de Piracicaba e Região.

O trabalho foi feito para compreender a relação entre queixas de sofrimento psíquico e o trabalhar a fim de descrever e transformar os diversos fatores determinantes das condições de trabalho dos ACS. O estudo foi realizado em uma USF, localizada em bairro de classe média baixa, de novembro de 2004 a maio de 2006, quando o relatório foi apresentado para a coordenação municipal da ESF. Cinco agentes de saúde compuseram a população sob estudo. A unidade foi escolhida por ser aquela que solicitou o estudo, desenvolvido após negociação junto aos trabalhadores e gestores da Secretaria de Saúde.

\section{Entendendo o problema: estado de saúde das ACS e margem de ação}

A solicitação para o estudo feita ao Cerest referia-se a queixas de sofrimento psíquico e estresse da maioria das ACS daquela unidade. Das cinco que compunham a equipe, quatro usavam medicamentos para pressão alta, sendo que duas estavam sendo medicadas também por apresentarem depressão. Para uma delas, o tratamento contra depressão havia sido iniciado apenas após o início do trabalho na Saúde da Família.

Haviam passado, recentemente, por atividades de suporte psicológico conduzidas por estudante de psicologia em programa de extensão universitária. ${ }^{4}$

Para a coordenadora da $\mathrm{ESF}^{5}$ municipal, até 2004, de acordo com entrevista realizada, não havia problema de adoecimento entre os agentes; o problema estava associado à falta de "perfil” para o trabalho. Embora acreditasse que os problemas de saúde não fossem restritos àquela equipe ou que, por meio do potencial da equipe, tais problemas poderiam ser superados, a coordenadora empossada em 2005 reconhecia a necessidade de "resiliência" para trabalhar na SF, discurso oficial do Ministério da Saúde, também compartilhado pela enfermeira da USF.

A despeito da complexidade e da dificuldade da missão que cabia (cabe) às ACS e da falta de meios para cumpri-la, as queixas das ACS eram consideradas problema individual e, portanto, não relacionadas ao trabalho. As interações iniciais com as trabalhadoras conduziam, no entanto, para outra direção, isto é, para a relação entre "sofrimento" e o engajamento no trabalho. Proposta feita sob esta perspectiva foi apresentada e acatada pelas ACS após negociação com a equipe e com os gestores da Secretaria.

\footnotetext{
${ }^{4}$ Que se encerraram após a formatura da estudante.

${ }^{5}$ Em Piracicaba, existiam, na época do estudo, 25 equipes de PSF - compostas por 1 médico, 1 enfermeira, 2 auxiliares de enfermagem e 6 ACS

-, que atuavam em bairros periféricos, com população de baixo poder aquisitivo e com pouco acesso aos recursos de saúde.
} 


\section{Aspectos metodológicos}

A Análise Ergonômica do Trabalhado se baseia em algumas premissas:

- A atividade de trabalho não se resume nunca à simples execução da tarefa prescrita. Para atender aos requisitos da tarefa, os trabalhadores desenvolvem estratégias, conscientes ou não, individuais e coletivas, a fim de lidar com as diversas formas de variabilidade. De modo geral, tais estratégias não são reconhecidas nas instituições ou nas empresas.

- Efeitos à saúde dos trabalhadores e à produção associam-se a fatores presentes na situação (equipamentos, organização, procedimentos, dentre outros) e ao poder de agir dos trabalhadores (de desenvolver tais estratégias). A análise da atividade baseada em observações cuidadosas e em entrevistas com os trabalhadores permite revelar as estratégias empregadas, as competências dos trabalhadores e os fatores que constrangem a realização da atividade.

Dada a importância da dimensão relacional no trabalho das ACS, que ocorre em uma "situação de serviço", adotou-se, como foco central do estudo, as "situações de interação” (CERF; FALZON, 2005) entre agentes e usuários, em especial as visitas domiciliares.

\section{Procedimentos e aspectos éticos}

O estudo foi apoiado pelo Cerest para atender indicação oriunda da Conferência Regional de Saúde do Trabalhador e Saúde Ambiental.

Foram realizadas observações em situação real de trabalho, seguidas de verbalizações das trabalhadoras para complementar o entendimento das situações vivenciadas.

Além disso, foram:

- realizadas entrevistas com agentes e gestores sobre diversos aspectos: funcionamento do programa, organização da unidade, dentre outros;

- analisados documentos e dados disponíveis a fim de descrever: o funcionamento e a produção do serviço, as atribuições das ACS, as características da população etc.;

- observadas atividades realizadas na USF - grupos de trabalhos terapêuticos, tarefas administrativas, planejamento diário - e fora dela: visitas domiciliares, outras atividades;

- feitas validações das observações realizadas e do relatório escrito com grupo de ACS e demais integrantes da equipe estudada e apresentado relatório final à Coordenação Municipal da ESF.

O total de horas de entrevistas, observações e análises foi de 180 horas.

Alguns procedimentos de ordem ética que norteiam a prática da Ergonomia e seguem o código de deontologia estabelecido pela Associação Brasileira de Ergo- nomia (ABERGO, 2003) foram seguidos, assim como algumas precauções foram tomadas, a saber:

- os sujeitos da pesquisa foram informados previamente sobre o estudo e concordaram com sua participação, tendo assinado termo de consentimento livre e esclarecido;

- o estudo foi autorizado formalmente pelo gestor municipal;

- os resultados foram validados e restituídos aos participantes;

- para evitar constrangimentos dos usuários durante as visitas domiciliares, as interações não foram gravadas, apenas anotadas em caderno;

- nomes e determinadas informações foram mantidos em sigilo e não reportados.

\section{Resultados}

\section{Características da organização e do funcionamento da USF}

A unidade situava-se em bairro periférico da cidade de Piracicaba, habitada por trabalhadores de baixa renda, funcionários públicos e aposentados. O território era dividido em cinco microáreas, atribuídas a cada ACS. Estas microáreas possuíam, em média, 350 moradores, totalizando a cobertura de uma população de 1.873 habitantes, que pertenciam a 502 famílias.

Conforme constava do Sistema de Informação da Atenção Básica (SIAB), 20\% desta população possuía mais de 50 anos, grupo que exigia maior cuidado de saúde. Entre os moradores, estavam cadastrados, em dezembro de 2004, 16 gestantes, 4 delas menores de 14 anos, e um contingente importante de moradores portadores de doenças e agravos: 253 possuíam hipertensão; 67 tinham diabetes; 17 tinham algum tipo de deficiência; 11 eram alcoólatras; 3 eram portadores de doença de chagas e 2 tinham epilepsia.

Para cuidar dessa população, a equipe era composta por um médico, uma enfermeira, duas auxiliares de enfermagem e cinco ACS do sexo feminino. Os profissionais de nível médio e superior eram concursados e as ACS, na época do estudo, contratadas por uma organização não governamental. Todos possuíam salário fixo acrescido de abono de assiduidade que poderia ser subtraído em caso de faltas e mesmo de doenças.

A unidade funcionava de acordo com um planejamento previamente estabelecido, desenhado segundo os programas definidos pelo Ministério da Saúde e pela Secretaria Municipal, a saber: saúde da criança, saúde da mulher, controle de hipertensão, controle do diabetes, controle da tuberculose, eliminação da hanseníase.

A vacinação era quinzenal e as consultas médicas e de enfermagem eram diárias, bem como outros proce- 
dimentos de enfermagem: curativos, aplicação de medicamentos injetáveis, dentre outros. A recepção fazia o agendamento de consultas internas e externas e o agendamento de exames para o nível central.

Com relação às ACS, o trabalho era dividido da seguinte forma: uma ACS se ocupava da recepção (onde era feito o agendamento de consultas internas e externas e de exames), enquanto as demais se dedicavam às atividades de rua ou às atividades educativas. As terças-feiras à tarde eram reservadas às reuniões semanais da equipe. Duas vezes por semana, as ACS e os demais membros da equipe promoviam caminhadas com pacientes pelo bairro.

Diariamente, as ACS realizavam visitas domiciliares (VD) em seu território, sendo reservados dias específicos para VDs acompanhadas pelo médico ou pela enfermeira.

Durante 2005, as metas mensais de VDs, fixadas pela coordenação, passaram de 504 a 1004, ou seja, aproximadamente duas VDs por família. As VDs realizadas em 2005 encontram-se no Quadro 1 abaixo.

O suporte de retaguarda para as 25 USF e as 26 Unidades Básicas de Saúde (UBS) existentes no município em 2005, no que se refere aos exames e às consultas com especialistas, era realizado por um único centro de especialidades, que, na ocasião, oferecia tais serviços mediante fila de espera, que poderiam durar meses para vários deles (Quadro 2).
Aspectos do trabalhar das ACS: impedimentos e engajamento na ação

\section{Percepção das ACS sobre suas atribuições e sobre o programa}

Como apresentado anteriormente, cabe às ACS a construção do vínculo com os usuários do serviço. O cerne do seu trabalho consiste na interação com as famílias, realizando diversas atividades com vistas à promoção da saúde e/ou à execução de pequenos cuidados.

No entanto, como dito acima, eram-lhes atribuídas tarefas administrativas - tais como atender na recepção, preenchimento de formulários, dentre outras - percebidas por elas de forma negativa, uma vez que exigiam tempo importante, que poderia ser empregado nas ações junto aos usuários.

O preenchimento de formulários era fundamental para a consolidação dos dados de produção da USF e dos indicadores de saúde centralizados na Coordenação da Secretaria Municipal. Dos 9 formulários usados, 8 eram preenchidos pelas ACS. Este preenchimento era vivenciado de forma trabalhosa pelas ACS. "É muito papel" - consideravam as ACS: "tem hora que a gente ou faz o serviço, ou preenche papel!”.

Quadro 1 Visitas domiciliares (VDs) realizados por mês em 2005

\begin{tabular}{|ccccccccccccc|}
\hline Mês & Janeiro & Fevereiro & Março & Abril & Maio & Junho & Julho & Agosto & Setembro & Outubro & Novembro & Dezembro \\
\hline VD & 540 & 609 & 418 & 675 & 954 & 882 & 682 & 986 & 881 & 840 & 814 & 689 \\
\hline
\end{tabular}

Fonte: Planilha do Sistema de Informação de Atenção Básica (SIAB)

Quadro 2 Tempo de espera para exames ou consultas com especialista em dezembro de 2005

\begin{tabular}{|lc|}
\hline \multicolumn{1}{|c|}{ Tipo de exame ou consulta } & Tempo de espera (dias) \\
\hline Ortopedista & $150-180$ \\
Dermatologista & $60-120$ \\
Otorrinolaringologista & $120-150$ \\
Oftalmologista & $150-210$ \\
Cirurgião geral & 7 \\
Cardiologista & 15 \\
Gastroenterologista & 0 \\
Neurologista & 30 \\
Médico do trabalho & $90-120$ \\
Ultrassom abdômen & $20-30$ \\
Ultrassom rins & $60-150$ \\
Ultrassom obstétrico & 60 \\
Ultrassom mama & 180 \\
Ultrassom abdômen total & 60 \\
Ultrassom pélvico & $30-60$ \\
Mamografia & 30 \\
Eletrocardiograma & 60 \\
\hline
\end{tabular}

Fonte: planilha de agendamento de especialistas e exames na USF 
De fato, assumiam para si próprias e para a equipe a missão institucional de cuidar e assistir a população adscrita. Uma das ACS afirmou:

No PSF é como se fizéssemos parte de uma grande família, uma família de 800 a 1000 casas [...] Somos responsáveis pelos resultados e pela situação de saúde de todo mundo. (ACS 1)

Consideravam a necessidade de envolvimento como a diferença, quando se comparava a SF aos demais serviços e seu papel na atenção à população, conforme a fala de outra ACS:

É muito diferente do que ocorre, por exemplo, em um pronto socorro [...] Quando termina a jornada às 17 horas, você vai para casa e esquece o resto [...] Não tem um envolvimento como no PSF [...] Aqui é diferente, você atende as pessoas em todo lugar, no ponto de ônibus, em casa, no supermercado no fim de semana [...] Aqui a pessoa tem que gostar do que faz [...] Tem que ter perfil [...] (ACS 3)

A jornada de trabalho se estendia, como afirmado, além do limite das 8 horas, assim como a vida privada perdia espaço, em várias ocasiões, para o trabalho. "[...] não existe um desligamento, as pessoas procuram ajuda, vão até em casa para obter alguma orientação [...]” (ACS 1). Segundo as ACS, isso ocorre inclusive durante as férias, pois, por falta de recursos para viajar, continuam no bairro sendo procuradas pelas pessoas.

\section{Necessidade do coletivo}

O engajamento no trabalho e o caráter intenso que a ele conferiam repercutiam em exigências ao funcionamento do coletivo. Daí a importância para elas da sua relação e de suas dificuldades com os demais membros da equipe, sendo que o funcionamento da equipe de maneira articulada era um dos fatores lembrados por todas para "cumprir a missão". "É necessário falar a mesma língua na equipe e ter sensibilidade para ouvir o outro [...] É como uma engrenagem [...] se uma peça falha, o resto é prejudicado" (ACS1).

Entre elas, as ACS afirmavam que, quando havia entrosamento, uma poderia ajudar a outra: "Quando uma está doente ou afastada, as colegas cobrem aquela área para não prejudicar o andamento do trabalho de visita” (ACS 4).

O disfuncionamento dessa engrenagem poderia surgir, segundo elas, devido às diversas formas de abordar o paciente pelos diferentes profissionais da equipe:

Acontece que às vezes o que o ACS levanta como problema do paciente não é valorizado por outros profissionais da equipe. (ACS 1)

Isso era explicado pelas ACS devido à diferença de formação dos profissionais, principalmente, do médico:

Enquanto ACS quer adotar o paciente, o médico tem um distanciamento [...] "Isso não é nada!" [...] fala o médico. (ACS 1)
Porque é impossível o médico conhecer cada paciente [...] Daí que entra a função do ACS. (ACS 1, 2, 3, 4 e 5)

Para exemplificar as dificuldades da engrenagem dizia: "Eu tenho uma paciente com dor na face há mais de um mês e ainda não consegui visita da médica [no domicílio]” (ACS 5).

Este fato revela que o sentido do trabalho da ACS poderia ser esvaziado caso "a engrenagem não funcione”, o que poderia gerar sofrimento. Comparavam a médica da equipe atual com a médica anterior: "a doutora anterior cobrava da gente retorno e a informação sobre os pacientes e a gente conhecia muito mais o paciente" (ACS 2).

\section{Influência da "percepção da comunidade" sobre o trabalho das ACS}

No entanto, o engajamento da equipe poderia não ser percebido positivamente pela comunidade. Alegavam que parte da população ainda não compreendera o trabalho delas e, por isso, não o reconhecia:

Tem gente que acha que a gente fica passeando pela rua o dia todo [...] Isto [a falta de reconhecimento] só não acontece com as crianças [...] Elas gostam do nosso trabalho e isto dá uma recompensa. (ACS 1)

O envolvimento de crianças e jovens era importante para elas, pois acreditavam que eles compreendiam melhor a SF do que vários adultos, o que seria fundamental para o futuro do serviço.

Atividades educativas de promoção da saúde junto aos jovens e a grupos de pacientes cujo funcionamento dependia de atividades lúdicas para obtenção de recursos materiais auxiliavam na criação de vínculo entre as ACS e os pacientes (e, portanto, com a unidade) e na efetividade de sua ação. "É assim que curamos uma pressão alta” explica a ACS durante a condução do bingo realizado na USF com grupo de idosos.

\section{Estratégias de enfrentamento das limitações da rede de serviços}

O engajamento das ACS não era suficiente para responder a todas necessidades em saúde da população, que dependia não apenas das competências dos demais membros da equipe, mas também dos demais serviços e especialidades que compunham a rede de serviços de saúde.

Para contornar a fila de espera, exames de urgência eram encaminhados via Pronto Socorro. Conforme observado, alguns casos ainda continuavam com espera acima de 6 meses, o que gerava reclamações e insatisfação na população, que descarregavam suas queixas nas ACS:

A pessoa volta como estava, fica desacreditada e vem reclamar com as ACS [...] O pior é que, da outra vez que encaminhamos, eles não vão mais, pois não acreditam que vai funcionar. (ACS 1) 
Como forma de regulação, as ACS e os demais membros da equipe, cientes que muitos usuários faltavam às consultas, afirmaram estar atentos para antecipar as possíveis faltas de usuários para substituí-los por pacientes que aguardavam na fila de espera. Para superar a falta de resposta do SUS, a equipe alegava "inventar caminhos" e conseguir, parcialmente, o que precisava.

Este caminho incluía, em 2004, triar os casos para médicos que elas conheciam e negociar vagas com outras unidades, dentre outras estratégias, a fim de tentar superar as dificuldades e obter suporte para as necessidades da população.

\section{Realidade e limites das visitas domiciliares (VD) como recurso para a ação}

As VD são o espaço principal para a construção das relações entre ACS e os usuários e o "meio" principal de que dispõem para participar na promoção e na preservação do estado de saúde destes usuários. ${ }^{6}$ Do ponto de vista gerencial, são as "operações" valorizadas que contam como produção da unidade.

Como é de se esperar, as ACS encontravam grande variedade de situações que exigiam recursos e conhecimentos diversos e maior ou menor envolvimento como mostra a verbalização a seguir:

\begin{abstract}
Na nossa vida não tem rotina, hoje parecia visita simples, mas não foi. Não tem planejamento, é como se fosse caixa de surpresa. Às vezes vai levar alguma coisa (pedido de exame, aviso, data de consulta marcada) e encontra coisa totalmente diferente, problema pelo caminho e o que ia fazer fica para outro dia. Já aconteceu de estar aqui (na Unidade) e ter que sair para ver emergência (pessoa passando mal, pressão elevada, intoxicação, acompanhar paciente ao PS porque a família não estava em casa), tem que ser na hora, não dá pra esperar. A responsabilidade é enorme, a gente não pensa, vai agindo, porque o nervoso fala mais alto. Às vezes também acontece de chamarem para ir à casa e não é nada daquilo. (ACS 2)
\end{abstract}

Evidentemente, na fala da ACS acima, não "cabem” todos os elementos de variabilidade das situações encontradas. Nas observações realizadas, uma série de fatores e eventos conferiam maior complexidade às situações devido a: características das pessoas e de seu estado, dos familiares e de sua disponibilidade nos cuidados, da dimensão afetiva durante interação, da gravidade das doenças ou dos cuidados, do tempo para se dedicar durante a VD, da possibilidade de envolver outros profissionais e serviços nos cuidados necessários, dos problemas sociais de risco à saúde (violência, drogas, relações conjugais e familiares violentas), do tipo de ação (orientação, acompanhamento, entrega de receita médica ou agendamento de consulta ou material para cuidado, dentre outras), enfim, da possibilidade de resolver os problemas.

Uma seleção de situações, observadas a partir das interações entre ACS e usuários, pode ser encontrada no Quadro 3, ilustrando a variabilidade citada acima.

Pode-se notar a diversidade de ações que empreendiam: orientação, entrega de documentos e materiais, apoio nos encaminhamentos, prestação de solidariedade e de conforto, solicitação de ajuda na alimentação, dentre outras. Precisavam valer-se de recursos, desde a família, os vizinhos e os outros profissionais; de saberes diversos, desde o saber viver determinadas leis, instituições, saúde e procedimentos.

A duração das VDs era extremamente variável, evidentemente, dependendo dos casos, das pessoas envolvidas e do dia (no final do mês, precisavam "colher assinaturas" com moradores para comprovação de visitas realizadas). Na visita, a Da. Z. ficou 62 minutos, na Da. P., apenas 5 minutos (Quadro 3).

As visitas, em alguns casos, eram resolutivas, como no caso do Sr. A., em que, devido à intervenção da ACS, adotou-se medicamento adequado e cuidados foram realizados pela Auxiliar de Enfermagem (que a ACS chamou). Em contrapartida, em boa parte das vezes, enfrentam situações em que pouco podem contribuir, como nos casos da Da. N., da Da. Z., do casal, da Da. H., da Da. M., do Sr. B., seja pelo tipo de problema de saúde, pela dificuldade em mobilizar outros profissionais e serviços da rede, seja pelo desamparo das pessoas - idosos com doenças crônico-degenerativas, problemas familiares e falta de recursos materiais. O que fazer?

No caso da Da. H., a ACS afirmou:

Vou até onde eu posso [...] Não posso tomar uma atitude pela família, e Da. H. não toma esta atitude por medo do filho [...] O que precisa ser feito eu sei [...] Contratar uma empregada remunerada, mas os filhos têm que chegar a uma conclusão sobre os cuidados [...], não consigo interferir na dinâmica da família. Toda a parte da saúde nós estamos fazendo, a consulta, internação etc.

No caso da Da. M., diante da dificuldade de internação no SUS, a ACS propõe-se a acompanhar a família até o hospital: "Vamos todos e fazemos um plantão até de madrugada [...] como já fizemos antes, lembra?” (ACS 4).

Os exemplos acima mostram que, ao entrar no espaço privado das pessoas, as ACS tomam conhecimento não apenas da (dura) realidade das pessoas e de suas famílias, de suas dificuldades e possibilidades, mas, sobretudo, das suas próprias realidades, das suas dificuldades e possibilidades, da sua margem de ação. Além disso, diante do quadro de desamparo de certas pessoas, seu envolvimento e sua implicação afetiva poderiam se tornar fonte de seu próprio adoecimento.

${ }^{6}$ Fundamental observar que certas famílias e pessoas não se interessavam pelo programa e, portanto, não queriam a presença das ACS em suas casas. O vínculo não pode ser imposto. 
Quadro 3 Seleção de visitas domiciliares (VDs) realizadas pelas Agentes Comunitárias da Saúde (ACS)

\begin{tabular}{|c|c|c|c|c|}
\hline$V D$ & Objeto da VD & Informações obtidas nas VDs & Ações & $\begin{array}{l}\text { Tempo } \\
\text { usado na } \\
\text { VD (min.) }\end{array}$ \\
\hline 1 & $\begin{array}{l}\text { Entrega de marcação de con- } \\
\text { sulta com ginecologista para } \\
\text { Da. N. }\end{array}$ & $\begin{array}{l}\text { Paciente sofria dor vaginal. } \\
\text { Teria de passar por especialista para } \\
\text { agendar ultrassom necessário para } \\
\text { seu diagnóstico. }\end{array}$ & & 20 \\
\hline 2 & $\begin{array}{l}\text { Acompanhar estado do paciente } \\
\text { Sr. A. em pós-operatório (hérnia), } \\
\text { após “intimação” do filho. }\end{array}$ & $\begin{array}{l}\text { Boa aparência, necessitava de anti- } \\
\text { inflamatório, mas era alérgico. } \\
\text { Faltava suporte familiar. }\end{array}$ & $\begin{array}{l}\text { Acalmou e orientou a família. } \\
\text { Chamou Auxiliar de Enfermagem, que } \\
\text { indicou medicação adequada, mediu } \\
\text { a pressão e fez curativo. }\end{array}$ & 45 \\
\hline 3 & $\begin{array}{l}\text { Acompanhar estado da Da. Z., } \\
\text { idosa, hipertensa, que mora } \\
\text { sozinha. }\end{array}$ & $\begin{array}{l}\text { Problemas na moradia, que era } \\
\text { precária. A mudança dependia do } \\
\text { filho. } \\
\text { Não estava usando medicamentos } \\
\text { por falta de dinheiro. } \\
\text { Lágrima da paciente durante VD. }\end{array}$ & $\begin{array}{l}\text { Orientou sobre estatuto do idoso. } \\
\text { Propôs-se a marcar encontro com o } \\
\text { filho. }\end{array}$ & 62 \\
\hline 4 & $\begin{array}{l}\text { Visitar (rotina) casal de aposen- } \\
\text { tados. }\end{array}$ & $\begin{array}{l}\text { Problema com filho drogado, que } \\
\text { morava nas ruas. }\end{array}$ & $\begin{array}{l}\text { Narrou experiência com o problema, } \\
\text { confortando o casal. Indicou terapia } \\
\text { de grupo para familiares. } \\
\text { Orientou sobre febre maculosa. }\end{array}$ & 43 \\
\hline 5 & $\begin{array}{l}\text { Acompanhar estado da Da. H., } \\
\text { idosa, diabética, hipertensa, que } \\
\text { mora com um dos filhos. }\end{array}$ & $\begin{array}{l}\text { Problemas familiares graves: filha, } \\
\text { que dela cuidava, a mal tratava e } \\
\text { usava drogas. Estava há } 3 \text { dias sem } \\
\text { comer. Mencionou intenção de se } \\
\text { matar. Tomava insulina. }\end{array}$ & $\begin{array}{l}\text { Conversou longamente, procurando } \\
\text { confortar paciente usando argumen- } \\
\text { tos religiosos. } \\
\text { Solicitou a vizinha a fornecer lanche. }\end{array}$ & 62 \\
\hline 6 & Visitar (rotina) o Domicílio. & $\begin{array}{l}\text { Conversou com a moradora sobre } \\
\text { situação de saúde da família. Situa- } \\
\text { ção normal sem problemas graves. }\end{array}$ & $\begin{array}{l}\text { Conversou e animou a moradora: } \\
\text { "Você está bem melhor agora, cortou } \\
\text { o cabelo? Está mais animada". Per- } \\
\text { guntou sobre medicação do marido. } \\
\text { Orientou sobre o que fazer com a se- } \\
\text { borreia da filha. Convidou a moradora } \\
\text { para participar do Bisqui na USF e do } \\
\text { passeio na rua do Porto que estava } \\
\text { sendo organizado pela equipe. }\end{array}$ & 18 \\
\hline 7 & $\begin{array}{l}\text { Acompanhar estado da Da. M., } \\
\text { idosa, hipertensa, cardiopata e } \\
\text { com grave problema lombar. }\end{array}$ & $\begin{array}{l}\text { Moradia razoável. } \\
\text { Necessitava de cirurgia e internação. }\end{array}$ & $\begin{array}{l}\text { Dispôs-se a acompanhá-la ao hospital } \\
\text { para tentar interná-la, pois não havia } \\
\text { conseguido mobilizar o médico da } \\
\text { UB. }\end{array}$ & 50 \\
\hline 8 & $\begin{array}{l}\text { Acompanhar estado do Sr. B., } \\
\text { com suspeita de CA e entregar } \\
\text { receita. }\end{array}$ & $\begin{array}{l}\text { Paciente apresentava verruga com } \\
\text { suspeita de câncer. Não se sentia } \\
\text { bem. } \\
\text { Havia sido solicitada consulta com } \\
\text { especialista, não marcada até aquele } \\
\text { momento. }\end{array}$ & $\begin{array}{l}\text { Conversou sobre a lesão. } \\
\text { Comprometeu-se a pressionar até } \\
\text { obter a consulta com especialista. }\end{array}$ & 8 \\
\hline 9 & $\begin{array}{l}\text { Entregar sonda urinária e } \\
\text { orientar paciente, Da. P., para } \\
\text { utilizá-la. }\end{array}$ & Paciente em cadeiras de rodas. & $\begin{array}{l}\text { Informou paciente sobre procedi- } \\
\text { mentos para retirar sonda junto ao } \\
\text { ambulatório de especialidades. }\end{array}$ & 5 \\
\hline
\end{tabular}




\section{O controle da produção versus a produção de cuidados}

Contraditoriamente, as ACS estavam sendo cobradas pela gestão municipal a assegurar não apenas 100\% de cobertura das moradias, mas que cada visita domiciliar fosse também comprovada por meio da assinatura dos moradores visitados.

Como consequência, observou-se que, nos dias próximos à "prestação de contas" - entrega do SIAB -, as ACS realizavam maior número de visitas domiciliares, em geral de curta duração, sendo que várias delas serviam apenas para "colher" assinaturas das visitas já realizadas:

No mês de setembro, três dias antes de entregar o cadastro para consolidar, faltavam 60 assinaturas e dei sorte de encontrar todas em casa... (ACS 2)

Nesses períodos, as agentes confrontavam-se com situações constrangedoras, tendo de solicitar assinaturas de pessoas contrárias ao programa:

Vai ter família que vai ficar constrangida porque, em todos esses anos, ainda não construí vínculo, elo. Tem uma moradora que não gosta de assinar. De primeiro não tinha obrigatoriedade, depois exigiram. Mês passado fui nela e pedi para assinar. Perguntou por que, se não usa o Posto (PSF) para nada. Expliquei a exigência, cadastro, assinatura para comprovar. Daí ela assinou. Isso foi no mês retrasado. Mês passado, novamente, ela aceitou. Entendeu que era para meu bem e disse que não vai fazer nada para dificultar minha vida. Também não é toda família que permite que faça visita dentro da casa. (ACS 2)

Por outro lado, como se observava, muitas casas se encontravam fechadas durante o dia, obrigando as ACS a ir até elas durante a noite ou nos finais de semana:

Agora temos que dar $100 \%$ de cobertura. Isto significa que temos que achar o morador a qualquer hora. Não pode ficar uma casa sem receber visita e tem que ser com o morador. Tem gente que só fica em casa de domingo ou nem isso. Alguns chegam depois das 23h. (ACS 4)

As exigências da coordenação configuravam-se como forma de negação da realidade: de um lado, exigiam produção máxima das ACS (de VDs, cujo aporte direto à saúde da comunidade é discutível), desconsiderando-se as limitações da rede de serviços. De outro, ao invés de dar suporte às atividades das ACS para enfrentar os casos difíceis e buscar soluções ante as limitações do sistema, focavam-se na "produção" de números a serem apresentados para as instâncias superiores de gestão. Nesta perspectiva, a VD era apenas um meio, como se fosse um "procedimento", não espaço (lugar e tempo) singular, privilegiado, onde a construção de relações e de vínculo com os usuários estava permanentemente em jogo.

\section{Recomendações}

Foram propostas algumas medidas, visando a aumentar o poder de agir das ACS, que podem ser agrupadas em duas categorias, segundo a viabilidade de sua implementação.

No primeiro grupo, onde se encontravam as medidas de implementação imediata, sugeriu-se:
- Repensar os atuais métodos de avaliação do trabalho das ACS, que atualmente só valorizam a quantidade de VDs, introduzindo, por exemplo, indicadores de saúde da população. Esta medida valorizaria os resultados alcançados pelo conjunto da equipe e aumentaria a margem de ação dos ACS, deixando mais espaço para os agentes enfrentar em situações complexas que requerem, mais tempo e articulação intersetorial;

- Realizar campanha na mídia para difundir as perspectivas da estratégia da saúde da família e a importância das visitas domiciliares, de modo a valorizar e facilitar o trabalho cotidiano dos agentes;

- Promover ações educativas, envolvendo todos os profissionais da equipe, simultaneamente, a fim de dotá-los de conhecimentos e habilidades requeridas e de articular a atuação coletiva, sobretudo, nos cuidados de casos complexos;

- Constituir grupo de suporte psicológico aos profissionais da equipe.

No segundo grupo, recomendou-se redesenhar os demais serviços da rede de saúde, ampliando sua capacidade de atendimento, diversificando a oferta de serviços e especialidades, a fim de atender a demanda da população e aproximar estes serviços às USFs. De forma análoga, medidas visando promover ações inter-setoriais e interinstitucionais envolvendo saúde, educação, assistência social, habitação, cultura e lazer, dentre outros setores da ação do Estado, foram sugeridas a fim de diminuir o isolamento das equipes de saúde da família no campo.

\section{Discussão}

O estudo conduzido pelo Cerest de Piracicaba possibilitou identificar a presença de fatores de risco para o sofrimento das ACS associados ao seu agir, sem se pretender produzir relação de causa e efeito entre o adoecer e sua situação de trabalho.

A análise do trabalho das ACS mostra que estas estavam engajadas na promoção da saúde das famílias sob suas responsabilidades. O que explica este engajamento? A análise dos resultados aponta para duas direções.

De um lado, o engajamento é semelhante ao que se observa na atividade de outros trabalhadores da saúde, cujo traço característico é a compaixão (MOLINIER, 2008). O trabalhar na saúde é voltado para o outro; assistir e cuidar visam a diminuir o sofrimento do outro. Segundo Fortuna (2003), "quem cuida quer ver a vida rebrotar” (p. 107). Este é o sentido, a essência do trabalho para o trabalhador em saúde, uma busca legítima pelo reconhecimento de que o outro se sinta cuidado e preferencialmente que se restabeleça, o que explica porque os trabalhadores tendem a cuidar primeiro do outro do que de si próprios (TEIGER; CLOUTIER; DAVID, 2005). 
De outro, o engajamento está associado ao próprio papel dos ACS de criação de vínculo com a comunidade, de estabelecer relação de confiança com as famílias que permitem o acesso ao seu mundo privado, a suas casas e que se justifica pelo "compromisso de promoção à saúde”. Este engajamento e sua implicação pessoal podem ser entendidos como a única saída possível quando o compromisso estabelecido entre as agentes e as famílias está em risco. Por exemplo, quando a continuidade da assistência não é possível, não é suficiente ou não atende às necessidades da família. Diante das limitações e dos impedimentos da rede de serviços e de demais serviços do Estado, a resposta das ACS, nessas situações, é seu engajamento pessoal (como no caso da ACS que se oferece para "fazer plantão" para tentar internar Da. M.), que não necessariamente resolverá o problema em tela e que pode levá-las ao adoecimento e ao sofrimento.

Jardim e Lancman (2009) constataram situação semelhante em seu estudo de Psicodinâmica do Trabalho (PDT) em agentes da sub-região de Pirituba, município de São Paulo, o que as levou a afirmar:

A falta de cadência entre a demanda da população e a disponibilidade dos serviços, ou seja, o insuficiente suporte do sistema de saúde e a impossibilidade de que o usuário tenha acesso a outros níveis de atenção dificultam as relações de confiança, ocasionando: conflitos pessoais, instabilidade nas relações de trabalho, prejuízos à produção, à qualidade do trabalho e ao atendimento prestado. (p. 131)

Assim, para essas autoras: o sofrimento decorre [...] da constatação da impossibilidade de solucionar as questões apresentadas e do contato constante e prolongado com essa população. Reflete a frustração vivenciada pelo agente devido: à dedicação que dispensa ao trabalho, à disponibilização do tempo, da energia física e psíquica, e à impossibilidade de resolução de problemas. (p. 131-132)

A missão idealizada pelo Ministério da Saúde, difundida como uma saída aos problemas da população, ao deixar de considerar os obstáculos, as dificuldades e os impedimentos que se interpõem a essa missão, coloca as ACS diante de uma encruzilhada: apesar de internalizarem o discurso idealizado, sentem na prática que boa parte de suas mensagens podem cair no vazio, o que pode gerar impotência, frustrações e sofrimento.

A inconsistência entre o que têm de fazer e o que foi possível realizar, fruto de seu engajamento, pode conduzir à perda de sentido do seu trabalhar, ou seja:

Um tipo de desligamento, que acontece na atividade, entre as preocupações reais dos trabalhadores - uma certa idéia do trabalho e deles mesmos, por exemplo - e as ocupações imediatas que caem em suas costas. O sentido mesmo da atividade realizada, da ação em curso, se perde mais freqüentemente quando desaparece no trabalho do sujeito ou dos sujeitos a relação entre objetivos aos quais se deve obedecer, os resultados que é preciso atingir e o que conta realmente para eles. O sentido da atividade realizada é a relação de valor que o sujeito instaura entre essa ação e as outras ações possíveis. (CLOT, 2008, p. 9)
Nesse sentido, o estudo mostrou também o aporte das instâncias de gestão para ampliar a perda do sentido do trabalhar dos agentes e para o agravamento dos conflitos ao fixar a meta de $100 \%$ dos domicílios como exigência para as VDs. Valorizou-se um "meio" e não os efeitos da contribuição do trabalho junto à comunidade, que poderiam ser avaliados pelos indicadores de saúde daquela população, o que demonstrava o desconhecimento dos gestores a respeito da realidade do trabalho das agentes.

Este estudo adotou perspectiva metodológica diferente da usada por Jardim e Lancman (2009), que se fundou na Psicodinâmica do Trabalho. Baseada na Ergonomia da Atividade e nos aportes recentes da Clínica do Trabalho (CLOT, 2006), a originalidade deste estudo encontra-se em se servir do potencial transformador da noção de "poder de agir".

A descrição dos fatores que determinam e influenciam em situação, para mais ou para menos, a capacidade de agir abre perspectivas concretas para a melhoria do trabalhar e para enfrentar os fatores determinantes do adoecimento. O que está em jogo, segundo Clot (2006), é "o desenvolvimento do poder de agir dos sujeitos em situação" (p.12), pois "quando a atividade individual e coletiva desenvolve seus objetivos, seus meios e seus móbiles, quando o raio de ação dos sujeitos pode aumentar, as emoções e cognições tornam-se então recursos do desenvolvimento" (p. 8) e, portanto, para a construção da sua saúde.

Nessa perspectiva, é fundamental ressaltar que existem serviços da ESF, como o que foi analisado por Silva e Athayde (2008, p. 33), cuja ação da coordenação em nível local ajuda a estabelecer uma "zona de desenvolvimento potencial" e uma nova dinâmica de trabalho, "potencializando o trabalho como operador de saúde”.

\section{Conclusão}

Ao estudar o cotidiano do trabalho dos ACS, deparou-se com a existência de conflitos e dificuldades enfrentadas pelas agentes para viabilizar a proposta da Saúde da Família no atual contexto do SUS. Possuidores de um forte vínculo com as famílias de sua microárea de abrangência, com dificuldade para colocar em prática estratégias para não somente aumentar seu poder de agir, mas também para se desligar dos problemas e minimizar os efeitos da carga de trabalho, as ACS tinham comportamento de doação absoluta no cuidado de um grande contingente de pessoas numa jornada que não acaba nunca.

Aliás, como mostram Jardim e Lancman (2009), o morar e o trabalhar na mesma comunidade determinam fundamentalmente o sofrimento dos trabalhadores devido ao "contato intenso e prolongado" que leva a "contaminação do tempo do não trabalho” (p. 133). 
O desenho do trabalho concebido pelos níveis centrais do programa empurra com "mão invisível" (VICENTE, 2005) os trabalhadores a buscar heroicamente uma resposta humanista e solidária às carências crônicas de cuidados de saúde da população.

Contudo, o Programa - a despeito de sua efetividade e papel na consolidação do SUS - não leva em conta o isolamento das unidades de saúde da família, os obstáculos pelo caminho e a falta de respostas a que ficam expostos os trabalhadores diante das carências da população e das dificuldades do próprio sistema de saúde.

A superação dos conflitos e das angústias da ESF passa pela implantação de medidas que possibilitem a estruturação descentralizada de uma rede de suporte intersetorial que envolva as áreas de saúde, desenvolvimento social, moradia, educação, trabalho e renda, cultura e lazer, dentre outras. Nesta direção, torna-se necessário, também, implantar e fortalecer os Núcleos de Apoio à Saúde da Família - NASF (BRASIL, 2008), de modo a agilizar e melhorar as ações de promoção de saúde e prevenção de doenças.

Só assim será possível vislumbrar a saúde, de fato, como direito de todos, ao proteger a saúde de quem cuida, pois a prevalência de agravos relacionados ao trabalho em servidores da saúde é o grande paradoxo que precisa ser enfrentado pelo SUS. Não parece ser aceitável que, para promover a saúde da população, a saúde dos trabalhadores da saúde esteja em risco (JACKSON; BARCELOS, 1999).

\section{Contribuição de autoria}

Os três autores participaram nas etapas de projeto e no delineamento do estudo, no levantamento, na análise e na interpretação de dados, na elaboração do manuscrito, na sua revisão crítica e finalmente na aprovação final da versão a ser publicada.

\section{Referências}

ABERGO. Norma ERG BR 102: código de deontologia do ergonomista certificado. Recife, 2003.

ASSUNÇÃO, A. A.; LIMA, F. P. A. Aproximações da ergonomia ao estudo das exigências afetivas da tarefa. In: GLINA, D. M. R.; Rocha, L. E. (Org.). Saúde Mental no Trabalho: da teoria à prática. São Paulo: Roca, 2010. p. 210-228.

AZEREDO, C. M. et al. Avaliação das condições de habitação e saneamento: a importância da visita domiciliar no contexto do programa de saúde da família. Ciência \& Saúde Coletiva, Rio de Janeiro, v. 12, n. 3, p. 743-753, 2007.

BRASIL. Ministério da Saúde. Secretaria de Assistência à Saúde. Saúde da família: uma estratégia para a reorientação do modelo assistencial. Brasília, 1997.

. Ministério da Saúde. Guia prático do programa saúde da família. Brasília, 2001.

. Ministério da Saúde. Secretaria de Gestão Estratégica e Participativa. Departamento de Monitoramento e Avaliação da Gestão do SUS. Painel de indicadores do SUS no 4. Temático Saúde da Família. Brasília, 2008.

CAMELO, S. H. H.; ANGERANI, E. L. S. Sintomas de estresse nos trabalhadores atuantes em cinco núcleos de saúde da família. Revista Latino-Americana de Enfermagem, Ribeirão Preto, v. 21, n. 1, p. 14-21, 2004.

CAMPOS, G. W. S. Subjetividade e administração de pessoal: considerações sobre modos de gerenciar o trabalho em equipes de saúde. In: MERHY E. E.;
ONOCKO R. T.(Org.). Agir em saúde um desafio para o público. São Paulo: Hucitec, 1997. p. 229-266.

CERF, M.; FALZON, P. Situations de service: travailler dans l'interaction. Paris: PUF, 2005.

CLOT, Y. A função psicológica do trabalho. Rio de Janeiro: Vozes, 2006.

. Travail et pouvoir d'agir. Paris: PUF, 2008.

DANIELLOU, F. Les TMS, symptôme d'une pathologie organisationnelle. BTS Newsletter, Bruxelles, n. 11/12, p. 34-37, 1999.

DANIELLOU F. A análise do trabalho: critérios de saúde, critérios de eficácia econômica. In: CASTILLO, J. J.; VILLENA, J. (Org.). Ergonomia: conceitos e métodos. Lisboa: Dinalivro, 2005. p. 233-245.

FORTUNA, C. M. Cuidando de quem cuida: notas cartográficas de uma intervenção institucional na montagem de uma equipe de saúde como engenhocamutante para produção da vida. 2003. 216 f. Tese (Doutorado em Enfermagem)-Universidade de São Paulo, Ribeirão Preto, 2003.

GUEDES, R. M. A.; LIMA, F. P. A.; ASSUNÇÃO, A. A. O programa de qualidade no setor hospitalar e as atividades reais da enfermagem: o caso da medicação. Ciência \& Saúde Coletiva, Rio de Janeiro, v. 10, n. 4, p. 1063-1074, 2005.

GUÉRIN, F. et al. Compreender o trabalho para transformá-lo. A prática da Ergonomia. São Paulo: Edgard Blücher, 2001. 
JACKSON, M.; BARCELOS, M. A. Entre a qualidade na promoção à saúde e a manutenção da própria saúde: as contradições do trabalho das agentes comunitárias da saúde do posto de saúde do Boeehmerwaldt: programa de saúde da família, Joinville. Relatório de pesquisa. Florianópolis: Fundacentro. Centro Estadual de Santa Catarina, 1999.

JARDIM, T. A.; LANCMAN, S. Aspectos subjetivos do morar e trabalhar na mesma comunidade: a realidade vivenciada pelo agente comunitário de saúde. Interface - Comunicação, Saúde, Educação, Botucatu, v. 13, n. 28, p. 123-135, 2009.

MARTINES, W. R. V.; CHAVES, E. C. Vulnerabilidade e sofrimento no trabalho do agente comunitário de saúde no programa de saúde da família. Revista da Escola de Enfermagem - USP, São Paulo, v. 41, n. 3, p. 426-433, 2006.

MOLINIER, P. A dimensão do cuidar no trabalho hospitalar: abordagem psicodinâmica do trabalho de enfermagem e dos serviços de manutenção. Revista Brasileira de Saúde Ocupacional, São Paulo, v. 33, n. 118, p. 06-16, 2008.

NUNES, M. O. et al. O agente comunitário de saúde: construção da identidade desse personagem híbrido e polifônico. Cadernos de Saúde Pública, Rio de Janeiro, v. 18, n. 6, p. 1639-1646, 2002.

PEDROSA, J. I. S.; TELES, J. B. M. Consenso e diferenças em equipes do programa de saúde da família. Revista de Saúde Pública, São Paulo, v. 35, n. 3, p. 303-11, 2001.

OLIVEIRA, S. F.; ALBUQUERQUE, F. J. B. Programa de saúde da família: uma análise a partir das crenças dos seus prestadores de serviço. Psicologia $\mathcal{\sigma}$ Sociedade, Florianópolis, v. 20, n. 2, p. 237-246, 2008.

RIBEIRO, E. M.; PIRES, D; BLANK, V. L. G. A teorização sobre processo de trabalho em saúde como instrumental para análise do trabalho no programa saúde da família Cadernos de Saúde Pública, Rio de Janeiro, v. 20, n. 2, p. 438-446, 2004.

SANTOS, V. C.; SOARES, C. B.; CAMPOS, C. M. S. A Relação trabalho-saúde de enfermeiros do PSF no município de São Paulo. Revista da Escola de Enfermagem - USP, São Paulo, v. 41, n. esp., p. 777781, 2007.
SCHIMITH, M. D.; LIMA, M. A. D. S. Acolhimento e vínculo em uma equipe do Programa de saúde da família. Cadernos de Saúde Pública, Rio de Janeiro, v. 20, n. 6, p. 1487-1494, 2004.

SILVA, J. A.; DAMASO, A. S. W. O Agente comunitário de saúde e suas atribuições: os desafios para os processos de formação de recursos humanos em saúde. Interface- Comunicação, Saúde, Educação, Botucatu, v. 6, n. 10, p. 75-96, 2002.

SILVA, A. C. B.; ATHAYDE, M. O programa de saúde da família sob o ponto de vista da atividade: uma análise das relações entre processos de trabalho, saúde e subjetivação. Revista Brasileira de Saúde Ocupacional, São Paulo, v. 33, n. 117, p. 23-35, 2008.

SILVA, I. Z. Q. J.; TRAD, L. A. B. O trabalho em equipe no PSF: investigando a articulação técnica e a interação entre os profissionais. Interface - Comunicação, Saúde, Educação, Botucatu, v. 9, n. 16, p. 25-38, 2005.

SZNELWAR, L. I.; ABRAHÃO, J. I.; MASCIA, F. Trabalhar em centrais de atendimento: a busca de sentido em tarefas esvaziadas. Revista Brasileira de Saúde Ocupacional, São Paulo, v. 31, n. 114, p. 97-112, 2006.

TEIGER, C.; CLOUTIER, E.; DAVID, H. Les activités de soin à domicile, soigner et prender soin. In: CERF, M. ; FALZON, P. Situations de service: travailler dans l'interaction. Paris: PUF, 2005. p. 179-204.

TOMASI, E. et al. Perfil sócio-demográfico e epidemiológico dos trabalhadores da atenção básica à saúde nas regiões Sul e Nordeste do Brasil. Cadernos de Saúde Pública, Rio de Janeiro, v. 24, Sup. 1, p. 5193-5201, 2008.

TRAVERSO-YÉPEZ, M.; BERNARDINO, J. M.; GOMES, L. O. "Fazem um PSF lá de cima...”: um estudo de caso. Psicologia em Estudo, Maringá, v. 12, n. 3 p. 593602, 2007.

VIANA, A. L. A.; DAL POZ, M. R. A reforma do sistema de saúde no Brasil e o programa de saúde da família. Physis: Revista de Saúde Coletiva, Rio de Janeiro, v. 8, n. 2, p. 11-48, 1998.

VALENTIM, I. V. L; KRUEL, A. J. A importância da confiança interpessoal para a consolidação do programa de Saúde da Família. Ciência \& Saúde Coletiva, Rio de Janeiro, v. 12, n. 3, p. 777-788, 2007.

VICENTE, K. Homens e máquinas. Rio de Janeiro: Ediouro, 2005. 